\title{
Features of the hydration process of the modified blended cement for fiber cement panels
}

\author{
Rustem Mukhametrakhimov ${ }^{1,}{ }^{1}{ }^{*}$, and Liliya Lukmanova $^{1}$ \\ ${ }^{1}$ Kazan State University of Architecture and Engineering, Zelenaya str., 1, Kazan, 420043, Russia
}

\begin{abstract}
The paper studies features of the hydration process of the modified blended cement for fiber cement panels (FCP) using differential thermal analysis, X-ray diffraction analysis, electron microscopy and infrared spectroscopy. It is found that deeper hydration process in silicate phase, denser and finer crystalline structure form in fiber cement matrix based on the modified blended cement. Generalization of this result to the case of fiber cement panels makes it possible to achieve formation of a denser and homogeneous structure with increased physical and mechanical properties.
\end{abstract}

\section{Introduction}

It is known that the correct use of active mineral admixtures (AMA) contributes to increase the strength and corrosion resistance of hardened cement paste, due to the formation of dense structures of low-basic calcium hydrosilicates [1,2]. Among the chemical additives for the modification of cement compositions, including fiber cement materials, the additives of hydrophobic-structuring action have the greatest influence on the formation of the structure, among which the most effective are organosilicon compounds (OSC) $[3,4]$.

Investigations of the properties of OSC and concrete with their use are described in the works of V.G. Batrakov [3-6], where it is established that the use of OSC allows to improve the physical and mechanical properties of concrete and substantially increase its durability, in particular, frost resistance. The modification of fiber cement materials by OSC, containing active functional groups, according to our data [7-8], makes it possible to significantly improve the complex of their properties and, first of all, their durability, especially during use of them in rough environment. However, analysis of the available data shows that the question of the impact of OSC on the physicomechanical properties and the durability of composite materials based on blended cement especially hardening during hydrothermal treatment remains insufficiently studied. Moreover, the impact of OSC on the formation of the structure and properties of fiber cement compositions based on combination of active mineral and flocculating admixtures remained to be considered. In our earlier studies [9-12], it was shown that modification of the composition of fiber cement panels (FCP) with active mineral and chemical admixtures makes it possible to

* Corresponding author: muhametrahimov@mail.ru 
significantly increase their physical and mechanical properties and durability, and also significantly reduce the consumption of the clinker of the blended cement.

\section{Materials and Methods}

The following materials were used in the research process:

- portland cement PTS500-D0 OAO Volskcement;

- ground quartz sand of Kama deposit GOST 8736-93;

- cellulose fibres NSK STO 00279189-2-2007 OAO Solombalski TSBK;

- the active mineral admixture of natural origin - metakaolin, obtained by calcination of kaolin at a temperature of $700{ }^{\circ} \mathrm{C}$ for 1 hour, specific surface area is $1357 \mathrm{~m} 2 / \mathrm{kg}$, chosen as the most effective by the results of previous studies [11];

- OSC FES-50 OAO Khimprom;

- flocculating additive for accelerating the filtration and precipitation of the solid phase, improving the filtration properties of the fiber cement formulation, and improving the structure of the FCP - polyacrylamide Besfloc K4046 KOLON LIFE SCIENCE, INC. (South Korea)

- piped drinking water GOST 23732.

The phase composition of the hydrated newgrowths of hardened cement paste, on the cement Volsky zavod M500 D0 $\mathrm{H}$ with the optimum content of modifying admixtures activated metakaolin (25\%), polyacrylamide (PAA - Besfloc K4046) with a high degree of ion charge $(0.1 \%)$, OSC (FES-50 - 0.1\% of the cement mass), subjected to autoclave curing, was studied by differential thermal analysis (DTA), X-ray diffraction analysis (XDA), electron microscopy and infrared spectroscopy.

\section{Results and Discussion}

Fig. 1 presents a complex structure of cementitious substance based on the initial (left) and modified blended cement (right).

1)

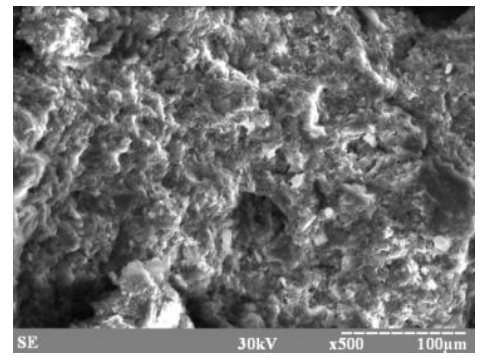

2)

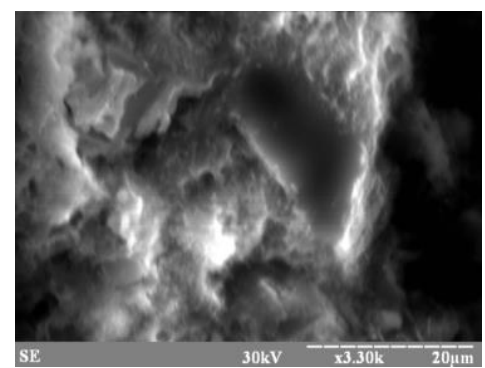

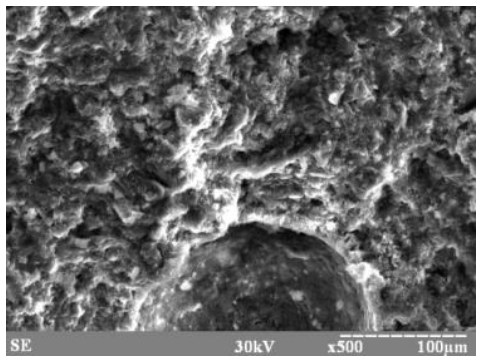

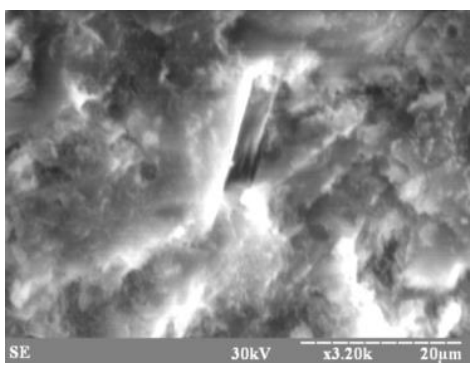

Fig. 1. Scanning electronic microscope (SEM) images of hardened cement paste samples based on the initial (left) and modified blended cement (right) after hydrothermal treatment magnified: $1-500$ times, 2 - 3200 times. 
On electron micrographs of hardened cement paste samples based on a modified blended cement, a denser and finer crystalline structure is observed, pores are filled with hydrated newgrowths, mainly low-basic calcium hydrosilicates, which leads to compaction and hardening of the material. The composition of the hydration products of the initial and modified blended cement was studied by XDA. X-ray diffraction patterns of the samples after hydrothermal treatment are shown in Fig. 2.

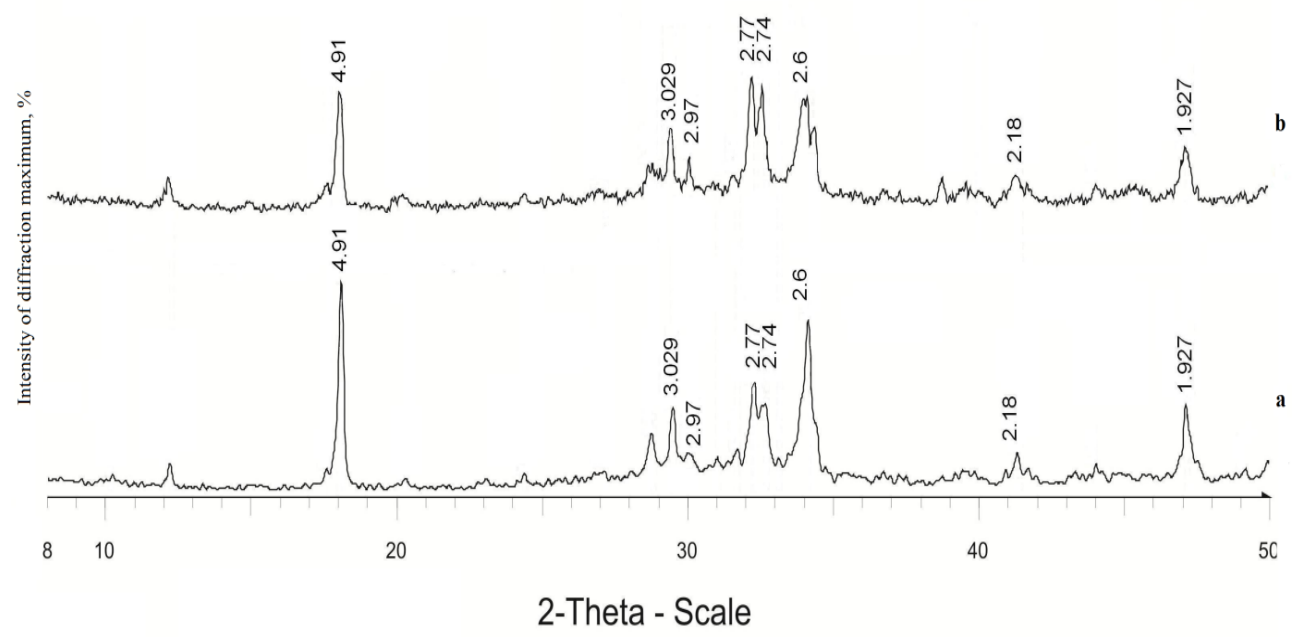

Fig. 2. XDA-curves of hardened cement paste samples based on initial (a) and modified (b) blended cement after hydrothermal treatment.

According to XDA data, the main products of hydration of the blended cement are portlandite $\left(4.91,2.6,1.927 \AA\right.$ ), hydrosilicate crystals $\mathrm{C}_{2} \mathrm{SH}_{2}$ with an interplanar distance $2.18 \AA$, crystals $\mathrm{C}_{2} \mathrm{SH}(\mathrm{C})-2.77 \AA$, low-basic hydrosilicates of the CSH (A) $-2.74 \AA$ and CSH (B) - $3.029 \AA$, and also tobomerite-like calcium hydrosilicates (HCS) with an interplanar distance $2.97 \AA$. The diffractogram of the sample based on the modified blended cement (Fig. 2b) is characterized by a significant increase in the amount of hydrosilicates $\mathrm{C}_{2} \mathrm{SH}(\mathrm{C})$ with an interplanar distance of $2.77 \AA$, low-lying HCS CSH (A) $(2.74 \AA)$ and tobermorite $(2.97 \AA)$, and a decrease the peaks of $\mathrm{Ca}(\mathrm{OH})_{2}$ and highly basic hydrosilicates of $\mathrm{C}_{2} \mathrm{SH}_{2}$ type $(2.18 \AA)$.

Studies of samples using DTA are shown in Fig. 3-4. As can be seen, the first endoeffect with a maximum at a temperature of $105-130{ }^{\circ} \mathrm{C}$ was noted on the DTA-curves of the samples based on initial and modified blended cement. This endoeffect is caused by the removal of loosely bound water from the gelatinous mass of the hardened cement paste. The second endoeffect with a maximum at $469-4700{ }^{\circ} \mathrm{C}$ is caused by the dehydration of calcium hydroxide and HCS. The third endoeffect is caused by the decomposition of calcium carbonate, as well as decomposition of HSC at a temperature of $710-7500{ }^{\circ} \mathrm{C}$. 


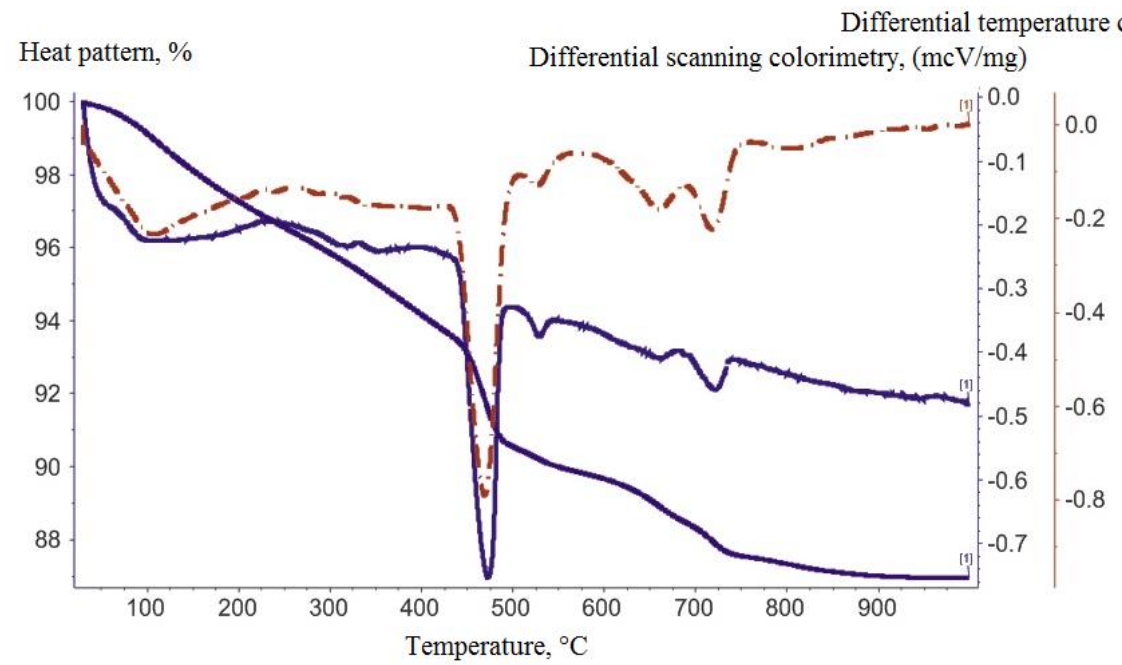

Fig. 3. DTA-curves of hardened cement paste samples based on initial blended cement after hydrothermal treatment.

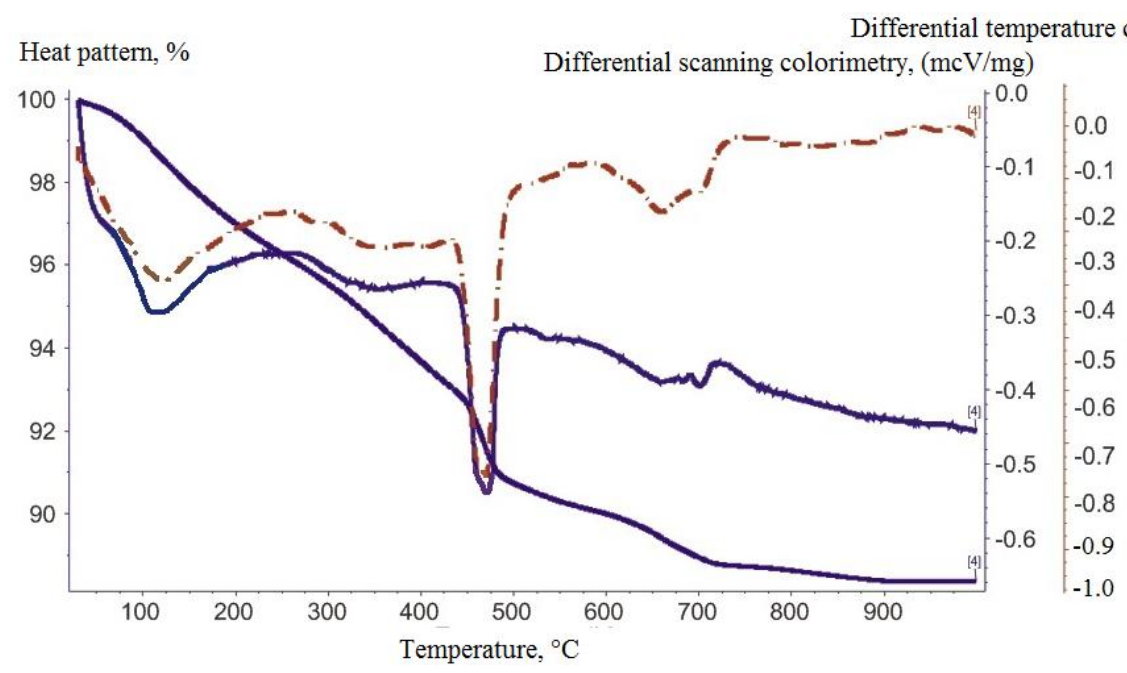

Fig. 4. DTA-curves of hardened cement paste samples based on modified blended cement after hydrothermal treatment.

The analysis of endo- and exothermic effects on the thermograms shows that in the samples based on the modified blended cement, a deeper hydration of the silicate phase of the cement occurs, as evidenced by an increase in the endothermic effect at a temperature of $160-170{ }^{\circ} \mathrm{C}$.

Research of the features of the phase of hydration products of the hardened cement paste based on the modified blended cement by the infrared spectroscopy (IR) method were performed on the Spectrum BXII infrared spectrometer using the method of incomplete internal reflection using the internal standard as a $\mathrm{KV}$.

The spectrograms of hardened cement paste are characterized by the presence of several specific maxima. Calcium hydrosulfoaluminate characterizes the presence of a maximum of the absorption band at $900-1000 \mathrm{~cm}^{-1}$. At the same time, a clearer solvability of the spectrum with a maximum of $1000 \mathrm{~cm}^{-1}$ indicates a better crystallization of calcium 
hydrosulfoaluminates in a hardened cement paste based on a modified blended cement. The maximum absorption at $1400-1600 \mathrm{~cm}^{-1}$ and wide spectral band in the $3300-3500 \mathrm{~cm}^{-1}$ region, indicates the presence of submicromite hydrosilicate submicrystal crystals, the content of which in the samples based on the modified blended cement is higher than in the composition based on the original binder. The good resolution of the spectrum in these regions indicates a higher degree of crystallization of the calcium hydrosilicates noted above in the hardened cement paste based on the modified blended cement. A narrow, wellresolved band of the absorption spectrum with a maximum of $3590-3650 \mathrm{~cm}^{-1}$ characterizes the presence of hydroxide hydrosilicates of the xonotlite group.

Analysis of the obtained results allows us to establish that the greatest absorption of the spectrum is observed at frequencies of $900-1000 \mathrm{~cm}^{-1}, 1400-1600 \mathrm{~cm}^{-1}, 3590-3650 \mathrm{~cm}^{-1}$. However, the highest intensity of the spectral lines is characteristic for a formulation based on a modified blended cement.

The review concluded that the reduced content of calcium hydroxide in samples based on the modified blended cement is due to the reactions of interaction AMA with the formation of HSC predominantly of low basic type. The features of the structure formation of the modified autoclaved FCP were studied by the determination of pore structure parameters and using scanning electron microscopy. Pore structure parameters of FCP, made on the basic of Volsk portland cement of grade 500D0 H, with the optimum content of AMA, polyacrylamide (PAA) and OSC were tested to GOST 12730.4-78.

Table 1 - Pore structure parameters of FCP

\begin{tabular}{|c|c|c|c|c|c|}
\hline & \multicolumn{5}{|c|}{ Pore structure parameters } \\
\cline { 2 - 6 } Formulation & $\begin{array}{l}\text { Total } \\
\text { pore } \\
\text { volume }\end{array}$ & $\begin{array}{l}\text { Volume of } \\
\text { open } \\
\text { capillary } \\
\text { pores }\end{array}$ & $\begin{array}{l}\text { Volume of } \\
\text { open non- } \\
\text { capillary } \\
\text { pores }\end{array}$ & $\begin{array}{l}\text { Volume of } \\
\text { conditionally } \\
\text { closed pores }\end{array}$ & Microporosity \\
\hline $\begin{array}{c}\text { based on initial } \\
\text { blended cement }\end{array}$ & 19.2 & 16 & 2.1 & 1.1 & 0.64 \\
\hline $\begin{array}{c}\text { based on modified } \\
\text { blended cement }\end{array}$ & 16 & 2.9 & 0.2 & 12.9 & 2.15 \\
\hline
\end{tabular}

As can be seen from Table 1, the modification of the formulation of FCP with admixtures reduces the total pore volume and changes the pore structure substantially. The total pore volume decreases from $19.2 \%$ to $16 \%$. With a simultaneous decrease in total pore volume, there is a significant redistribution of the volume of open capillary, open noncapillary and conditionally-closed pores. Thus, the volume of open non-capillary pores decreases from $2.1 \%$ to $0.2 \%$, the volume of open capillary pores decreases from $16 \%$ to $2.9 \%$, and the volume of conditionally-closed pores increases from 1.1 to $12.9 \%$. The microporosity increases from 0.64 to 2.15 .

The structure of FCP based on the modified blended cement was studied by scanning electron microscopy. SEM images of the samples, obtained by scanning electron microscope REM-100U, are presented in Fig. 5. 


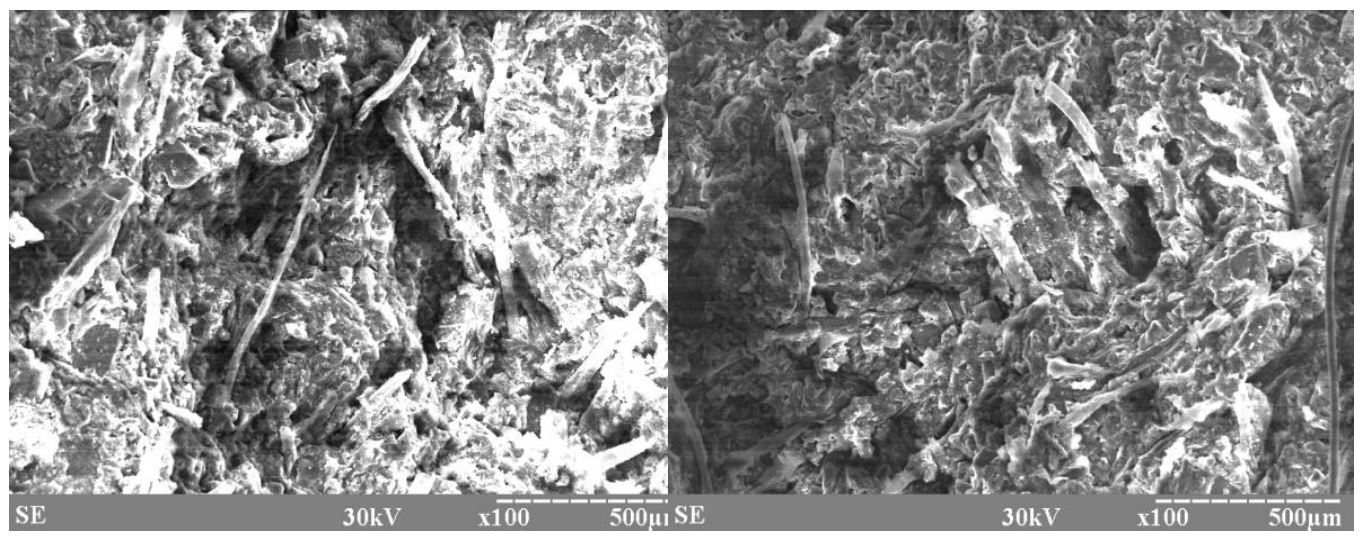

a)

b)

Fig. 5. SEM images of fracture site of FCP-samples based on the modified blended cement, magnified - 100 times.

As can be seen from SEM images (Fig. 5), the structure of the FCP is a strand of fine cellulose fibers that are connected to the monolith by the products of hydration of the blended cement. The presence of cellulose fibers determines the strength and rigidity of the conglomerate, the blended cement protects fiber against aggressive environmental influences, provides interaction between fibers under mechanical influences. Fig. 5 (a, b) shows a general picture of the structure of the cement fiber panel in the fracture site. The structure is characterized by a relatively homogeneous, chaotic distribution of cellulose fibers with separate inclusions of sand particles. The fibers are located predominantly parallel to the plane of pressing, which explains the increased bending strength.

\section{Conclusions}

- With the introduction of AMA into blended cement - activated metakaolin with waterinsoluble OSC and PAA of a high degree of ionic charge, an optimal capillary-porous structure of hardened cement paste is formed due to the increased volume of hydrated neoplasms, hydrophobization and changes in the structure of capillaries and pores (total pore volume is reduced by $0.2-3.2 \%$, open capillary pores $-13.1 \%$, open non-capillary pores $-1.9 \%$, the volume of conditionally closed pores is increased by $11.9 \%$, the microporosity increases by $1.51 \%$ ). This leads to increase of physical and mechanical properties and durability of FCP subjected to hydrothermal treatment on the basis of tested formulation.

- It has been established that in samples of hardened cement paste and FCP based on the modified blended cement, a denser, homogeneous and fine-grained structure is observed, pores are filled with hydrated neoplasms, mainly low-basic HSC, which leads to compaction and hardening of the material.

- The peculiarities of the influence of AMA and chemical additives on the formation of the micro- and macrostructure of the modified blended cement and FCP based on it under hydrothermal treatment were studied, from which it follows that the final products of hardening of the modified blended cement differ from the products of hardening of the initial binder significantly. The principal difference, as follows from the data of DTA, XDA and electron microscopy, is the reduced content of free $\mathrm{Ca}(\mathrm{OH})_{2}$, the high-basic HCS $\mathrm{C}_{2} \mathrm{SH}_{2}$ and the increased content of low-basic forms of hydrosilicates. The resulting hydrate 
neoplasms have a higher dispersity, compared with the products of hydration of the initial blended cement.

\section{References}

1. E.A. Gamaliy, B.Y. Trofimov, L.Y. Kramar, Vestnik Yuzhno-Ural'skogo gosudarstvennogo universiteta. Seriya: Stroitel'stvo i arkhitektura, 1629 (2009)

2. K. Lyuk, Y.Y. Lyakhovski, Tsement i yego primeneniye, 1116 (2011)

3. V.G.Batrakov, Povysheniye dolgovechnosti betona dobavkami kremniyorganicheskikh polimerov (Stroyizdat, Moscow, 1968)

4. V.G. Batrakov, Modifitsirovannyye betony (Stroyizdat, Moscow, 1998)

5. V.G. Batrakov, Povysheniye dolgovechnosti betona dobavkami kremniyorganicheskikh polimerov (Stroyizdat, Moscow, 1968)

6. V. Batrakov, S. Kapriyelov, ACI Int. Karter. po avansam v Konk. Tekhnologii. LasVegas 609 (1995)

7. R.Kh. Mukhametrakhimov, V.S. Izotov, Izvestiya KGASU, 4 (18) 254 (2011)

8. R.Kh. Mukhametrakhimov, L.V. Lukmanova, A.F. Khuzin, IOP Conference Series: Earth and Environmental Science, 90 (2017)

9. R.Kh. Mukhametrakhimov, V.S. Izotov, Izvestiya KGASU, 2 (16) 213 (2011)

10. R.Kh. Mukhametrakhimov, L.V. Lukmanova, Advances in Intelligent Systems and Computing, 692852 (2018)

11. R.Kh. Mukhametrakhimov, V.S. Izotov, Izvestiya vuzov. Stroitel'stvo, 9 (677) 101 (2012)

12. R.Kh. Mukhametrakhimov, V.S. Izotov, L.S. Sabitov, Stroitel'nyye materialy, 520 (2011) 